\title{
The Social Costs of Side Trading*
}

\author{
Andrea Attar ${ }^{\dagger} \quad$ Thomas Mariotti ${ }^{\ddagger} \quad$ François Salanié ${ }^{\S}$
}

March 23, 2020

\begin{abstract}
We study resource allocation under private information when the planner cannot prevent bilateral side trading between consumers and firms. Adverse selection and side trading severely restrict feasible trades: each marginal quantity must be fairly priced given the consumer types who purchase it. The resulting social costs are twofold. First, second-best efficiency and robustness to side trading are in general irreconcilable requirements. Second, there actually exists only one budget-feasible allocation robust to side trading, which deprives the planner from any capacity to redistribute resources between different types of consumers. We discuss the relevance of our results for insurance and financial markets.
\end{abstract}

Keywords: Adverse Selection, Side Trading, Second-Best Allocations. JEL Classification: D43, D82, D86.

*This paper supersedes the first part of "Multiple Contracting in Insurance Markets" (TSE Working Paper $\left.n^{\circ} 14-532\right)$ by the same authors. We thank the Editor, Gilat Levy, and three anonymous referees for very thoughtful and detailed comments. Financial support from the ANR (Programme d'Investissement d'Avenir ANR-17-EURE-0010) and the Chaire SCOR-TSE is gratefully acknowledged.

$\dagger$ Toulouse School of Economics, CNRS, University of Toulouse Capitole, Toulouse, France, and Università degli Studi di Roma "Tor Vergata," Roma, Italy. Email: andrea.attar@tse-fr.eu.

${ }^{\ddagger}$ Toulouse School of Economics, CNRS, University of Toulouse Capitole, Toulouse, France. Email: thomas.mariotti@tse-fr.eu.

§Toulouse School of Economics, INRA, University of Toulouse Capitole, Toulouse, France. Email: francois.salanie@tse-fr.eu . 


\section{Introduction}

The theory of incentives identifies the holding of private information by economic agents as a fundamental constraint on the allocation of resources (Hurwicz (1973)). Standard aggregate resource constraints must accordingly be supplemented by incentive-compatibility constraints that reflect the agents' ability to conceal their private information (Myerson $(1979,1982))$. The problem of the optimal allocation of resources then reduces to that of characterizing informationally constrained efficient, or second-best, allocations (Harris and Townsend (1981)). The key finding is that a tradeoff arises between redistribution and incentives (Mirrlees (1971)).

A crucial assumption of theories of the second-best is that, although individual types are unobservable, individual trades can be perfectly monitored by the planning authority. Because few, if any, economic institutions have the required ability to monitor all individual trades, this calls for an explicit consideration of the role of side trading in the theory of resource allocation under private information, as first pointed out by Hammond (1979).

To this end, we consider a general environment in which firms can provide a divisible good to privately informed consumers who may be of two types. Consumers' preferences satisfy a single-crossing condition, and there is adverse selection in that consumers who are more willing to trade are also more costly to serve; private values arise as a limiting case when consumers' types are not payoff-relevant for the firms selling to them. This framework encompasses many applications, including the standard Rothschild and Stiglitz (1976) insurance economy as a prominent example.

In this setting, we characterize the allocations that can be achieved by a planner who observes neither consumers' types nor the trades they may conduct with firms. To do so, we refine the standard notion of incentive-feasibility by focusing on allocations that are robust to side trading. This reflects two additional constraints on resource allocation. First, the planner cannot force consumers to trade with him; this is the case, for instance, when consumers can opt out of a publicly provided health-insurance plan, as in the current German system. Second, he cannot prevent them from engaging in mutually advantageous additional trades with a firm. We formalize these constraints by requiring the planner to offer a tariff such that no firm, acting as an entrant, can guarantee itself a positive profit by offering complementary side trades. This approach provides us with a modified criterion of incentive feasibility which is useful for evaluating the social costs of side trading. Focusing on twotype environments affords us a straightforward comparison with standard characterizations of the second-best efficiency frontier in both private-value (Bierbrauer and Boyer (2014)) and common-value (Prescott and Townsend (1984), Crocker and Snow (1985), Bisin and 
Gottardi (2006)) environments.

We show that the social costs of side trading are twofold. First, second-best allocations are typically not robust to side trading, so that the planner's inability to monitor consumers' trades has significant welfare implications. Second, only one budget-feasible allocation is robust to side trading, so that the third-best efficiency frontier reduces to a point: the threat of side trading effectively deprives the planner from any capacity to redistribute resources between different types of consumers. The allocation we characterize is thus the natural candidate for a competitive equilibrium, but, being the only feasible one under side trading, little, if anything, can be argued about its desirability.

A distinctive feature of our approach is that we model side trade as bilateral contracts between a consumer and a firm. This reflects our dissatisfaction with the standard way of representing unobservable side trades as transactions on Walrasian markets, which would call for a centralized market institution to ensure that all these trades take place at the same price. Bilateral trading plays a key role in our analysis. Our key Lemma 1, in particular, shows that budget-feasible allocations robust to side trading have a very peculiar price structure: each marginal quantity, or layer, is priced at the cost of serving the types who purchase it. This form of competitive pricing, reminiscent of Akerlof (1970), implies that there are no crosssubsidies between these layers, though there may be cross-subsidies between types. When the allocation is interior and separating, linear pricing can emerge only in the private-value limiting case.

Lemma 1 has a simple but important implication that we state in Theorem 1: no secondbest allocation in which only one incentive compatibility-constraint binds is robust to side trading. The reason is that, by the standard efficiency-at-the-top property, consumers for which this constraint binds must trade at the margin at the cost of serving them. As a result, the layer that connects the trades of the two types cannot be priced at the cost of serving the type who is the most willing to trade. But then, by Lemma 1, there always exists some side trade that a firm finds it profitable to conduct with at least one consumer type. For instance, in the Rothschild and Stiglitz (1976) insurance economy, any second-best allocation in which the high-risk type's incentive-compatibility constraint binds can be exploited by an entrant offering complementary coverage at a premium rate slightly higher than the high-risk fair premium rate, which this type is willing to trade along with the coverage provided by the allocation for the low-risk type.

Our second main result, Theorem 2, states that, among the allocations that feature no cross-subsidies between layers, only one is robust to side trading, namely, the Pareto-efficient one that maximizes the utility of the consumer type who is the less willing to trade. This uniqueness result stands in stark contrast with the nondegenerate second-best efficiency 
frontier that emerges from the standard tradeoff between redistribution and incentives. To complete our characterization, we evaluate whether this allocation can be second-best, hence considering the situations not covered by Theorem 1. Theorem 3 shows that a second-best allocation robust to side trading must either feature pooling of the two consumers' types, or each type purchasing her first-best quantity. We argue that these situations can only occur under very special assumptions on preferences and costs. Thus the unique third-best allocation typically does not belong to the second-best efficiency frontier.

\section{Related Literature}

While the constraints induced by private information on resource allocation are by now well understood, less is known about the impact of side trading on feasibility and redistribution. Starting with the early contributions of Hammond (1979, 1987), Allen (1985), and Jacklin (1987), several authors have attempted to identify the limits to risk sharing generated by consumers' side trading in financial markets. Cole and Kocherlakota (2001), Golosov and Tsyvinski (2007), Farhi, Golosov, and Tsyvinski (2009) have analyzed different private-value environments in which the planner is constrained by the existence of Walrasian markets on which privately informed consumers can complement their trades with the planner by trading linearly priced commodities. This raises two sets of questions, which we address in this paper. First, the existence of unobservable transactions is at odds with the idea that all trades take place in a centralized Walrasian market where a single market-clearing price is quoted - the issue is not so much that the quantities traded are unobservable, which is consistent with the functioning of a Walrasian market, but rather that side trades may take place at different prices and that bilateral contracting prevents the planner from monitoring the terms of these trades. Second, if one sticks to the Walrasian paradigm, extending the approach to incorporate common values and adverse selection presents severe conceptual difficulties (Prescott and Townsend (1984), Rustichini and Siconolfi (2008)); a possible way out is to rely on an Akerlof-like (1970) equilibrium, which however only obtains under linear utilities and/or indivisibilities (Attar, Mariotti, and Salanié (2011), Philippon and Skreta (2012), Tirole (2012)). We hence depart from the above literature in two ways. First, we offer an alternative representation of side trading, which we essentially regard as a bilateral rather than a centralized process. Second, we focus on trade under common values; hence, in a bilateral relationship, a firm's profit directly depends on the types of the consumers it trades with, which is arguably a prominent feature of insurance and financial markets.

The constraints induced by private contracting on redistribution between workers who are privately informed of their productivities have also been investigated by Stantcheva (2014) in the context of optimal taxation. In her framework, however, the State retains 
full observability of workers' total incomes, as in Mirrlees (1971), which severely limits their ability to engage in side trading.

Our requirement that an allocation must be implementable by an entry-proof tariff to be robust to side trading is in line with the definition by Kahn and Mookherjee (1998) or Bisin and Guaitoli (2004) of third-best allocations in moral-hazard environments. In any such allocation, the planner's tariff must prevent consumers from complementing it with an additional profit-making contract provided by a firm. We extend this notion to privateinformation environments, and, in addition, we put no restriction on the side trades a firm can make available.

The unique third-best allocation that we characterize has been formerly derived by Glosten (1994) and Attar, Mariotti, and Salanié (2019a) as the outcome of competitive financial markets where market makers are restricted to post collections of limit orders and insiders thus face a convex aggregate tariff. In contrast with these authors, we adopt a fully normative perspective. This requires imposing no restriction on sides trades, which we assume to be fully bilateral. In line with this assumption, we allow firms to react to the planner's tariff by posting arbitrary tariffs. Jaynes (1978), Hellwig (1988), and Stiglitz, Yun, and Kosenko (2018) show that this allocation can also be obtained in an equilibrium of a modified Rothschild and Stiglitz (1976) insurance economy in which insurance companies can exchange information about their customers. Although the allocation is the same, the logic of our approach is entirely different. First, these authors allow firms to react to the information disclosed by their competitors by possibly enforcing exclusivity clauses, which is at odds with the very notion of side trading that we emphasize. Second, as noticed above, we are interested in the normative implications of side trading and not in characterizing the equilibrium of a given extensive-form game. We return to the issue of the decentralization of the third-best allocation in Section 4.

Our analysis shares with the common-agency literature (Martimort (2007)) the idea that what can be implemented by a principal-here, the planner-crucially depends on the trades made available by other principals - here, an entrant. Our normative approach, however, differs from the fully strategic approach adopted, in a similar environment, by Attar, Mariotti, and Salanié (2014). The idea is that when a planner contemplates implementing an allocation by a tariff, he always anticipates that an entrant, acting as a follower, may complement this tariff by providing consumers with further trading opportunities. The requirement that the planner's tariff be entry-proof then captures in a natural way the additional constraints that the possibility of side trades imposes on the planner.

The paper is organized as follows. Section 2 describes the model. Section 3 defines our 
concept of robustness to side trading, fully characterizes the only feasible allocation satisfying this requirement, and shows that it is typically not second-best. Section 4 discusses the relevance of our results for insurance and financial markets. Proofs not given in the text can be found in the Appendix.

\section{The Economy}

Consumers There is a continuum of consumers who can purchase a divisible good in exchange for monetary transfers. Each consumer is privately informed of her type $i=1,2$ and the proportion of type $i$ among consumers is $m_{i}>0$. Type $i$ 's preferences over quantitytransfer bundles $(q, t) \in \mathbb{R}_{+} \times \mathbb{R}$ are represented by a strictly quasiconcave and continuously differentiable utility function $u_{i}$, with $\partial_{t} u_{i}<0$. Hence her marginal rate of substitution

$$
\tau_{i} \equiv-\frac{\partial_{q} u_{i}}{\partial_{t} u_{i}}
$$

is well defined and strictly decreasing along her indifference curves. We impose the Inada condition that $\tau_{i}(q, t)$ vanishes as $q$ grows large along any such curve. Hence, whatever her endowment point, type $i$ 's demand at any price $p>0$ is finite. The following strict single-crossing condition is the key determinant of consumer demand:

$$
\text { For all } q \text { and } t, \tau_{2}(q, t)>\tau_{1}(q, t) \text {. }
$$

Thus type 2 is more willing to increase her purchases than type 1.

Firms The supply side of the economy is described by a constant-return-to-scale technology, with unit $\operatorname{cost} c_{i}>0$ of serving type $i$. Type 2 is weakly more costly to serve than type 1 :

$$
c_{2} \geq c_{1}
$$

Together with (1), (2) typically generates adverse selection, whereas values are private in the limiting case $c_{1}=c_{2}$. We let $c \equiv m_{1} c_{1}+m_{2} c_{2}$ be the average cost of serving a consumer.

These assumptions hold in the Rothschild and Stiglitz (1976) insurance economy: $c_{i}$ is type $i$ 's riskiness, with $c_{2}>c_{1}, q$ is the amount of coverage she purchases, and $t$ is the premium she pays in return. Our model encompasses many other specifications and is relevant for a broad spectrum of insurance, financial, and labor markets.

Incentive Feasibility and Efficiency A contract is a pair $(q, t)$ for some $q \geq 0$, and with unit price $t / q$ if $q>0$. An allocation is a pair of contracts, one for each type. An allocation $\left(q_{i}, t_{i}\right)_{i=1,2}$ is budget-feasible if

$$
m_{1}\left(t_{1}-c_{1} q_{1}\right)+m_{2}\left(t_{2}-c_{2} q_{2}\right) \geq 0 \text {. }
$$


To this aggregate resource constraint, we must add, following Myerson (1979, 1982) and Harris and Townsend (1981), constraints reflecting that the allocation of resources takes place under asymmetric information. An allocation $\left(q_{i}, t_{i}\right)_{i=1,2}$ is incentive-compatible if

$$
u_{1}\left(q_{1}, t_{1}\right) \geq u_{1}\left(q_{2}, t_{2}\right) \text { and } u_{2}\left(q_{2}, t_{2}\right) \geq u_{2}\left(q_{1}, t_{1}\right) .
$$

We denote these constraints by $I C_{1 \rightarrow 2}$ and $I C_{2 \rightarrow 1}$, respectively. An allocation is incentivefeasible if it is budget-feasible and incentive-compatible. A second-best allocation is Paretoefficient among incentive-feasible allocations. This is the relevant notion of efficiency for a planner who perfectly monitors trades, but does not observe consumer types (Prescott and Townsend (1984)). In the Rothschild and Stiglitz (1976) insurance economy, the second-best efficiency frontier consists of a continuum of allocations (Crocker and Snow (1985), Bisin and Gottardi (2006)).

Tariffs A tariff $T$ is a schedule specifying a transfer $T(q)$ to be paid in return for a quantity $q$, with $T(0)=0$ in case a consumer chooses not to trade along the tariff and $T(q)=\infty$ in case the tariff does not allow consumers to purchase the quantity $q$. A tariff $T$ implements the allocation $\left(q_{i}, t_{i}\right)_{i=1,2}$ if

For each $i, q_{i} \in \arg \max \left\{u_{i}(q, T(q)): q \geq 0\right\}$ and $t_{i}=T\left(q_{i}\right)$.

To ensure that the various maximization problems we will encounter have solutions, we impose the mild requirement that a tariff be lower semicontinuous, with $T(q) / q$ bounded away from 0 as $q$ grows large; this notably holds true if $T$ has a compact domain.

\section{Second-Best Allocations and Side Trading}

When side trading is feasible, the planner can no longer monitor trades between consumers and firms. This imposes two additional constraints on resource allocation. First, the planner cannot force consumers to trade with him, reflecting that they can opt out of any mechanism he could propose. To model this constraint, we require that the planner offer a tariff $T^{P}$, the key restriction being $T^{P}(0)=0$. Second, the planner cannot prevent consumers from engaging in mutually advantageous additional trades with a firm. To model this constraint, we require that $T^{P}$ be such that no firm, acting as an entrant, can guarantee itself a positive profit by offering complementary side trades.

Side trades are usually assumed to take place on Walrasian markets (Hammond (1979, 1987), Allen (1985), Jacklin (1987), Cole and Kocherlakota (2001), Golosov and Tsyvinski (2007), Farhi, Golosov, and Tsyvinski (2009)); in our context, this would amount to impose that the entrant must post a linear tariff. We find this at odds with the idea that side 
trades cannot be monitored and instead allow the entrant to post an arbitrary tariff $T^{E}$; the taxation principle (Hammond (1979), Guesnerie (1981), Rochet (1985)) ensures that this involves no loss of generality. Notice that we do not thereby prevent the entrant from offering a linear tariff; rather, the key idea is that the entrant can choose the terms of side trades and restrict the set of quantities consumers can choose from. This motivates the following definition.

Definition 1 The planner's tariff $T^{P}$ is entry-proof if, for any entrant's tariff $T^{E}$, there exists a solution $\left(q_{i}^{P}, q_{i}^{E}\right)$ to each type $i$ 's problem

$$
\max \left\{U_{i}\left(q^{P}+q^{E}, T^{P}\left(q^{P}\right)+T^{E}\left(q^{E}\right)\right): q^{P} \geq 0 \text { and } q^{E} \geq 0\right\}
$$

such that entry is not profitable:

$$
m_{1}\left[T^{E}\left(q_{1}^{E}\right)-c_{1} q_{1}^{E}\right]+m_{2}\left[T^{E}\left(q_{2}^{E}\right)-c_{2} q_{2}^{E}\right] \leq 0
$$

An allocation is robust to side trading if it can be implemented by an entry-proof tariff.

It may at first be objected that we are tilting the odds in the planner's favor by de facto assuming that he is able, in case consumers are indifferent, to coordinate their behavior on an allocation in which the entrant does poorly. However, this assumption plays no role in the characterization results we offer in Theorems 1-3: indeed, Theorem 2 shows that this arguably weak entry-proofness concept already singles out a unique budget-feasible allocation robust to side trading; moreover, the necessary conditions we derive are obtained using contracts that are profitable for the entrant no matter the consumers' best responses. By contrast, strengthening our entry-proofness concept - for instance, by requiring that the planner's tariff be robust to entry no matter the consumers' best responses - would threaten the very existence of a budget-balanced allocation robust to side trading. This situation, however, is hardly specific to our model: indeed, when sustaining equilibria of competitive adverse-selection models, it is often necessary to assume that firms cannot sort out the least costly types at the deviation stage in case consumers are indifferent. ${ }^{1}$

Any allocation robust to side trading is incentive-compatible. The question we ask is whether such an allocation can also be second-best. Our argument is twofold.

On the one hand, budget-feasible allocations robust to side trading have the following price structure.

Lemma 1 In any budget-feasible allocation $\left(q_{i}, t_{i}\right)_{i=1,2}$ robust to side trading,

$$
t_{1}=c q_{1} \text { and } t_{2}-t_{1}=c_{2}\left(q_{2}-q_{1}\right) .
$$

\footnotetext{
${ }^{1}$ This in particular the case when the equilibrium allocation involves some amount of pooling, as in Akerlof (1970), Miyazaki (1977), Wilson (1977), Spence (1978), and Attar, Mariotti, and Salanié (2011).
} 
Proof. Because an allocation $\left(q_{i}, t_{i}\right)_{i=1,2}$ robust to side trading is incentive-compatible, it satisfies $q_{2} \geq q_{1}$ by single crossing. Moreover,

$$
t_{1} \leq c q_{1}
$$

Otherwise, an entrant can supply $q_{1}$ at a price slightly above $c$ : this profitably attracts type 1 as $T^{P}(0)=0$, and remains profitable even if type 2 is attracted. Similarly,

$$
t_{2}-t_{1} \leq c_{2}\left(q_{2}-q_{1}\right)
$$

Otherwise, an entrant can supply $q_{2}-q_{1}$ at a price slightly above $c_{2}$ : this profitably attracts type 2 along with the contract $\left(q_{1}, t_{1}\right)$, and is even more profitable if type 1 is also attracted. Rewriting the resource constraint as

$$
t_{1}-c q_{1}+m_{2}\left[t_{2}-t_{1}-c_{2}\left(q_{2}-q_{1}\right)\right] \geq 0
$$

and taking advantage of (6)-(7) yields (5). The result follows.

Hence pricing is competitive, in the sense that the prices of the layers $q_{1}$ and $q_{2}-q_{1}$ reflect the costs of serving the types who purchases them. However, if $c_{2}>c_{1}$ and $q_{1}>0$, then the quantities $q_{1}$ and $q_{2}$ are not priced competitively: as $q_{1}$ is sold at the average cost $c>c_{1}$, type 1 subsidizes type 2 .

On the other hand, second-best allocations satisfy the following efficiency-at-the-top property.

Lemma 2 In any second-best allocation $\left(q_{i}, t_{i}\right)_{i=1,2}$,

(i) If $I C_{2 \rightarrow 1}$ is slack, then $\tau_{1}\left(q_{1}, t_{1}\right) \leq c_{1}$, with equality if $q_{1}>0$.

(ii) If $I C_{1 \rightarrow 2}$ is slack, then $\tau_{2}\left(q_{2}, t_{2}\right)=c_{2}$.

Proof. If $I C_{2 \rightarrow 1}$ or $I C_{1 \rightarrow 2}$ is slack, then $q_{2}>q_{1}$ by incentive compatibility and single crossing. If $I C_{2 \rightarrow 1}$ is slack and $\tau_{1}\left(q_{1}, t_{1}\right)>c_{1}$, then $\left(\left(q_{1}+\varepsilon, t_{1}+c_{1} \varepsilon\right),\left(q_{2}, t_{2}\right)\right)$ is incentivefeasible for $\varepsilon>0$ small enough and Pareto-dominates $\left(q_{i}, t_{i}\right)_{i=1,2}$, a contradiction. Thus $\tau_{1}\left(q_{1}, t_{1}\right) \leq c_{1}$. Moreover, if $q_{1}>0$ and $\tau_{1}\left(q_{1}, t_{1}\right)<c_{1}$, then $\left(\left(q_{1}-\varepsilon, t_{1}-c_{1} \varepsilon\right),\left(q_{2}, t_{2}\right)\right)$ is incentive-feasible for $\varepsilon>0$ small enough and Pareto-dominates $\left(q_{i}, t_{i}\right)_{i=1,2}$, once again a contradiction. This proves (i). The proof of (ii) is similar, using $q_{2}>0$, and is therefore omitted. The result follows.

Combining Lemmas 1 and 2 yields our first main theorem. 
Theorem 1 A second-best allocation in which only one incentive-compatibility constraint binds is not robust to side trading.

Proof. Suppose first that only $I C_{1 \rightarrow 2}$ binds. Then $q_{2}>q_{1}$ by incentive compatibility and single crossing, and $\tau_{1}\left(q_{1}, t_{1}\right) \leq c_{1}$ by Lemma 2(i). Moreover, because type 1 's preferences are strictly convex and $I C_{1 \rightarrow 2}$ binds, we have $t_{2}-t_{1}<c_{1}\left(q_{2}-q_{1}\right) \leq c_{2}\left(q_{2}-q_{1}\right)$. By Lemma $1,\left(q_{i}, t_{i}\right)_{i=1,2}$ is not robust to side trading.

Suppose next that only $I C_{2 \rightarrow 1}$ binds. Then $q_{2}>q_{1}$ by incentive compatibility and single crossing, and $\tau_{2}\left(q_{2}, t_{2}\right)=c_{2}$ by Lemma 2(ii). Moreover, because type 2's preferences are strictly convex and $I C_{2 \rightarrow 1}$ binds, we have $t_{2}-t_{1}>c_{2}\left(q_{2}-q_{1}\right)$. By Lemma $1,\left(q_{i}, t_{i}\right)_{i=1,2}$ is not robust to side trading. Hence the result.

Theorem 1 covers most cases emphasized in the literature. For instance, in the Rothschild and Stiglitz (1976) insurance economy, either $I C_{1 \rightarrow 2}$ or $I C_{2 \rightarrow 1}$ bind in all but the pooling second-best allocation (Crocker and Snow (1985)), and Theorem 1 implies that none of these allocations is robust to side trading.

This leaves only two cases in which a second-best allocation may be robust to side trading: when both $I C_{1 \rightarrow 2}$ and $I C_{2 \rightarrow 1}$ bind, which corresponds to a pooling allocation, or when both $I C_{1 \rightarrow 2}$ and $I C_{2 \rightarrow 1}$ are slack. Both cases can arise, as we show below, but only under very special assumptions on preferences and costs.

To study these cases, we strengthen Lemma 1 by establishing that a unique allocation is budget-feasible and robust to side trading. In this allocation, the first layer is optimal for type 1 at price $c$, while the second layer is optimal for type 2 at price $c_{2}$, conditional on her purchasing the first layer. This allocation is thus Pareto-efficient-maximizing type 1's utility - among those satisfying (5).

Theorem 2 The third-best allocation defined by

$$
\begin{aligned}
q_{1}^{*} & \equiv \arg \max \left\{u_{1}(q, c q): q \geq 0\right\} \\
t_{1}^{*} & \equiv c q_{1}^{*} \\
q_{2}^{*} & \equiv q_{1}^{*}+\arg \max \left\{u_{2}\left(q_{1}^{*}+q, t_{1}^{*}+c_{2} q\right): q \geq 0\right\} \\
t_{2}^{*} & \equiv t_{1}^{*}+c_{2}\left(q_{2}^{*}-q_{1}^{*}\right),
\end{aligned}
$$

is the only budget-feasible allocation robust to side trading.

Proof. (Uniqueness) Because an allocation $\left(q_{i}, t_{i}\right)_{i=1,2}$ robust to side trading is incentivecompatible, it satisfies $q_{2} \geq q_{1}$ by single crossing. Moreover,

$$
u_{1}\left(q_{1}, t_{1}\right) \geq \max \left\{u_{1}(q, c q): q \geq 0\right\}
$$


Otherwise, an entrant can offer a contract with unit price slightly above $c$ that profitably attracts type 1 as $T^{P}(0)=0$, and remains profitable even if type 2 is attracted. Similarly,

$$
u_{2}\left(q_{2}, t_{2}\right) \geq \max \left\{u_{2}\left(q_{1}+q, t_{1}+c_{2} q\right): q \geq 0\right\} .
$$

Otherwise, an entrant can offer a contract with unit price slightly above $c_{2}$ that profitably attracts type 2 along with the contract $\left(q_{1}, t_{1}\right)$, and is even more profitable if type 1 is also attracted. Finally, if $\left(q_{i}, t_{i}\right)_{i=1,2}$ is budget-feasible, then (5) holds, so that (12)-(13) are equalities. Thus $\left(q_{i}, t_{i}\right)_{i=1,2}$ is the third-best allocation defined by (8)-(11).

(Existence) By (8)-(11), the piecewise-linear convex tariff

$$
T^{P}(q) \equiv 1_{\left\{q \leq Q_{1}^{*}\right\}} c q+1_{\left\{q>Q_{1}^{*}\right\}}\left[c q_{1}^{*}+c_{2}\left(q-q_{1}^{*}\right)\right]
$$

implements the third-best allocation. Now, suppose that an entrant posts a tariff $T^{E}$. The following monotonicity property is established in the Appendix.

Lemma 3 There exists a solution $\left(\left(q_{i}^{P}, q_{i}^{E}\right)\right)_{i=1,2}$ to (3) such that $q_{2}^{E} \geq q_{1}^{E}$.

Let us fix such a solution in what follows. As $T^{P}$ allows type 1 to purchase her optimal quantity $q_{1}^{*}$ at price $c$, we must have

$$
T^{E}\left(q_{1}^{E}\right) \leq c q_{1}^{E}
$$

Moreover, because $q_{2}^{E} \geq q_{1}^{E}$, type 2 could alternatively obtain the same aggregate quantity $q_{2}^{P}+q_{2}^{E}$ as in her best response by purchasing $q_{1}^{E}$ from the entrant and $q_{2}^{P}+q_{2}^{E}-q_{1}^{E}$ from the planner, paying overall $T^{P}\left(q_{2}^{P}+q_{2}^{E}-q_{1}^{E}\right)+T^{E}\left(q_{1}^{E}\right)$. As she chooses to pay $T^{P}\left(q_{2}^{P}\right)+T^{E}\left(q_{2}^{E}\right)$ instead, we must have

$$
T^{E}\left(q_{2}^{E}\right)-T^{E}\left(q_{1}^{E}\right) \leq T^{P}\left(q_{2}^{P}+q_{2}^{E}-q_{1}^{E}\right)-T^{P}\left(q_{2}^{P}\right) .
$$

Because $T^{P}$ is convex with slope at most $c_{2}$ and $q_{2}^{E} \geq q_{1}^{E}$,

$$
T^{P}\left(q_{2}^{P}+q_{2}^{E}-q_{1}^{E}\right)-T^{P}\left(q_{2}^{P}\right) \leq c_{2}\left(q_{2}^{E}-q_{1}^{E}\right)
$$

Collecting (15) and (16)-(17) yields

$$
T^{E}\left(q_{1}^{E}\right)-c q_{1}^{E}+m_{2}\left[T^{E}\left(q_{2}^{E}\right)-T^{E}\left(q_{1}^{E}\right)-c_{2}\left(q_{2}^{E}-q_{1}^{E}\right)\right] \leq 0,
$$

which is (4). This shows that $T^{P}$ is entry-proof. Hence the result.

The uniqueness of the third-best allocation contrasts with the multiplicity of second-best allocations, which form a nondegenerate frontier. The planner is thus severely constrained by 
his inability to monitor trades, which effectively prevents any kind of redistribution between different types of consumers.

The existence of such an allocation for any binary distribution of types is also noteworthy. Nonexclusivity, or consumers' ability to combine the contracts offered by an entrant with those offered by the planner, is key to this result. While this enlarges the set of contracts an entrant can use to attract consumers, this also gives the planner more instruments to deter entry. These take the form of latent contracts, which are not meant to be traded but only to make entry unprofitable. Of course, the planner must make sure that, by offering latent contracts, he does not create new profitable entry opportunities. The third-best tariff (14) strikes a balance between these two requirements.

In the adverse-selection case $c_{2}>c_{1}$, type 1's and type 2's marginal rates of substitution at the third-best allocation are strictly ordered, $\tau_{1}\left(q_{1}^{*}, t_{1}^{*}\right)<\tau_{2}\left(q_{2}^{*}, t_{2}^{*}\right)$. In particular, we have $\tau_{1}\left(q_{1}^{*}, t_{1}^{*}\right)=c<c_{2}=\tau_{2}\left(q_{2}^{*}, t_{2}^{*}\right)$ if the third-best allocation is interior and separating. This contrasts with private-value models where side trades take place on Walrasian markets, which calls for an equalization of marginal rates of substitution (Hammond $(1979,1987)$ ). Yet incentive-compatible gains from trade between types 1 and 2 are exhausted at the thirdbest allocation, subject to the side-trading constraint. Indeed, supposing that consumers have access to the same constant-return-to-scale technology as firms, the minimum price at which type 1 would be willing to sell a small additional quantity to type 2 is $c_{2}$, and at this price type 2 is not willing to buy. In that sense, the third-best allocation is the only candidate for a competitive equilibrium.

Regarding the proof of Theorem 2, an interesting duality is that the third-best allocation is the only candidate for a budget-feasible allocation robust to side trading even if the entrant can only offer a single contract, while the third-best tariff is entry-proof even if the entrant can post an arbitrary tariff. This differs from Glosten (1994), who in his analysis of limitorder markets requires the entrant's tariff to satisfy a property he dubs single crossing and that generalizes convexity. Another important difference is that Theorem 2 does not require consumers' preferences to be quasilinear, which makes it relevant for standard insurance economies.

We are now ready to address the remaining cases not covered by Theorem 1.

Theorem 3 If a second-best allocation is robust to side trading, then it coincides with the third-best allocation and one of the following conditions holds:

(i) The third-best allocation is pooling, that is, $\tau_{2}\left(q_{1}^{*}, t_{1}^{*}\right) \leq c_{2}$.

(ii) The third-best allocation is separating and first-best, that is, $c_{1}=c_{2}$ or $\tau_{1}(0,0) \leq c_{1}$. 
Proof. By Theorem 2, if a second-best allocation is robust to side trading, then it coincides with the third-best allocation. By Theorem 1, we only need to consider two cases.

(i) If $I C_{1 \rightarrow 2}$ and $I C_{2 \rightarrow 1}$ bind, then $q_{2}^{*}=q_{1}^{*}$ by incentive compatibility and single crossing. Hence the third-best allocation is pooling, which amounts to $\tau_{2}\left(q_{1}^{*}, t_{1}^{*}\right) \leq c_{2}$ by $(10)-(11)$.

(ii) If $I C_{1 \rightarrow 2}$ and $I C_{2 \rightarrow 1}$ are slack, then $q_{2}^{*}>q_{1}^{*}$ by incentive compatibility and single crossing. Hence the third-best allocation is separating. Two cases can arise. If $q_{1}^{*}>0$, then $\tau_{1}\left(q_{1}^{*}, t_{1}^{*}\right)=c_{1}$ by Lemma $2(\mathrm{i})$ and $\tau_{1}\left(q_{1}^{*}, t_{1}^{*}\right)=c$ by $(8)-(9)$, so that $c_{1}=c_{2}$. If $q_{1}^{*}=0$, then $\tau_{1}(0,0) \leq c_{1}$ by Lemma $2(\mathrm{i})$. In either case, each type $i$ trades efficiently at $\operatorname{cost} c_{i}$, so that the third-best allocation is first-best. Hence the result.

Condition (i) is clearly extreme. It cannot hold in a Rothschild and Stiglitz (1976) insurance economy, because the optimal coverage of type 1 at the average premium rate $c$ is only partial, while type 2 is willing to purchase additional coverage at the fair premium rate $c_{2}$ until she reaches full insurance. In the case of quasilinear preferences, condition (i) together with the condition $\tau_{1}\left(q_{1}^{*}, t_{1}^{*}\right) \leq c$ implied by (8)-(9) entails that type 1's first-best quantity is at least as large as type 2's, and strictly larger if $q_{1}^{*}>0$, a case of nonresponsiveness (Caillaud, Guesnerie, Rey, and Tirole (1988)).

Condition (ii) is also extreme. Indeed, the third-best allocation is then first-best, and the third-best tariff is linear with slope $c_{2}$. In the private-value case $c_{1}=c_{2}$, each type trades efficiently at marginal cost. In the adverse-selection case $c_{2}>c_{1}$, a separating second-best allocation is robust to side trading only if type 1 is not willing to trade at $\operatorname{cost} c_{1}$ and hence is in some sense irrelevant.

This answers the question we raised in this section: second-best efficiency and robustness to side trading are irreconcilable requirements, except in very special cases. Overall, our results suggest that the threat of side trading constitutes a serious obstacle to efficiency and redistribution in private-information economies. In the limiting case of private values, side trading poses no threat to efficiency, as it leads to a first-best allocation; yet the requirement that there be no cross-subsidies between layers precludes the planner from redistributing resources between different consumer types. By contrast, under adverse selection, the social costs of side trading are twofold: first, the threat of side trading moves the economy away from the second-best efficiency frontier; second, it precludes redistribution.

\section{Decentralization and Market Intervention}

The Decentralization Problem Determining whether constrained-efficient allocations can be supported in an equilibrium of an adverse-selection economy is a central issue for welfare economics. Bisin and Gottardi (2006) provide a positive answer to this question in 
the case of fully observable trades: for any second-best allocation, there exists a system of transfers ensuring that this allocation obtains in an equilibrium of a decentralized economy in which firms compete by offering exclusive contracts. However, in the polar case where firms can only observe their own trades with consumers, decentralizing a third-best allocation is a more delicate task. To perform it, one needs to explicitly model firms' behavior when no information on consumers' aggregate trades is available to them.

In perfectly competitive markets, it is standard to assume, following Bisin and Gottardi (1999), that nonexclusive competition forces prices to be linear. Yet, as Theorem 3 shows, this is consistent with third-best efficiency only in the special private-value case. A natural alternative is to consider strategic models in which firms compete through menus of bilateral contracts. Side trading is then captured by letting consumers free to trade with any subset of firms, in contrast with the exclusivity assumption made in standard competitive screening models following Rothschild and Stiglitz (1976).

Attar, Mariotti, and Salanié (2014) provide a general analysis of this nonexclusivecompetition scenario. Their main result is that a positive level of trade for type 2 can be supported in a pure-strategy equilibrium only if type 1 is left out of the market. Indeed, equilibrium requires that type 1 not be willing to consume at price $c$, and type 2 purchasing her optimal quantity at price $c_{2}$. Given (8)-(11), the resulting equilibrium allocation is a degenerate third-best one in which $\left(q_{1}^{*}, t_{1}^{*}\right)=(0,0)$. A necessary and sufficient condition for decentralization is $\tau_{1}(0,0) \leq c$, that is, Akerlof's (1970) condition for a market breakdown in which only the worse-quality goods are traded. In all other cases, a pure-strategy equilibrium fails to exist altogether.

An alternative strategy that has been pursued in the literature consists in designing extensive-form games that incorporate inter-firm communication. This approach, initiated by Jaynes (1978) and Hellwig (1988), and further developed by Stiglitz, Yun, and Kosenko (2018), allows each firm to dynamically react to the information about its customers' trades disclosed by its competitors. This may induce a firm to withdraw its initial offers or to enforce exclusivity clauses, which suggests that these models are better interpreted as models of endogenous exclusivity than of side trading. In addition, enforcing any such mode of communication would require a very sophisticated institutional setting to properly take into account firms' incentives to reveal information over time.

By contrast, we suggest below some simple market interventions that decentralize the third-best allocation. The novelty of our proposal consists in the explicit consideration of public programs that the agents can complement by resorting to the private sector, therefore endogenously determining the aggregate level of trade. Their simplicity lies in the fact that little information is required for public authorities. We develop our discussion in the context 
of insurance and financial markets.

Insurance Markets In modern health-insurance systems, public insurance schemes for the provision of basic coverage do not prevent an active role for the private sector. In Germany, consumers can opt out from the public-insurance scheme to buy basic coverage designed and priced by private insurance companies. Consumers also often have the option to complement basic coverage with additional privately provided coverage, such as mutuelles in France. Finally, different forms of mandatory health insurance, whereby consumers are not allowed to remain uninsured, are in place in several systems, as in France, Germany, Japan, Netherlands, and Switzerland. ${ }^{2}$

Our analysis suggests a simple intervention that achieves a mix of public and private insurance, with no need for observability requirements. It consists in letting the State offer any amount of basic coverage up to $q_{1}^{*}$ at the average premium rate $c$. As private insurance companies are willing to provide any amount of complementary coverage at the high premium rate $c_{2}$, the State together with any insurance company make the third-best tariff available. Because this tariff is entry-proof, no insurance company has an incentive to deviate and entry is impossible. Implementing the third-best allocation is therefore compatible with letting consumers free to choose their preferred level of coverage. This is reminiscent of the universal health-care vouchers advocated by Emanuel and Fuchs (2005, 2007), whereby universal coverage is provided while letting consumers free to purchase additional services or amenities on private insurance markets.

Financial Markets In the aftermath of the recent crisis, the opportunity for agents to opt out of a public program and trade in private markets has been acknowledged as a key constraint for the design of financial institutions in the presence of adverse selection. In this respect, recent works have suggested a rationale for liquidity-injection programs that provide a credible signal to uninformed lenders by rejuvenating the relevant markets. An optimal intervention then typically consists in attracting only the least profitable borrowers, either through direct lending (Philippon and Skreta (2012)), or by repurchasing low-quality assets (Tirole (2012)). By participating in a bailout program, a borrower may however end up signalling her financial weakness to the market, creating a stigma effect with potentially perverse implications (Gorton (2015)).

While bailout policies are derived under the assumption that public and private liquidity are mutually exclusive, our approach offers a general theoretical framework for evaluating public interventions in situations where privately informed borrowers may complement a

\footnotetext{
${ }^{2}$ We refer to the surveys of Thomson and Mossialos (2009) and Thomson, Osborne, Squires, and Jun (2013) for institutional details and cross-country evidence.
} 
public program with additional funds raised on private markets. A possible intervention would require public liquidity provision to involve a price sufficiently low, $c$, so as to attract all borrowers, and a borrowing limit $q_{1}^{*}$ such that no overborrowing by the least profitable ones is possible. Further borrowing may then take place on private markets at price $c_{2}$. Overall, such an intervention would implement the third-best allocation, thereby achieving budget balance, unlike those proposed by Philippon and Skreta (2012) and Tirole (2012), and inducing all types of borrowers to participate. This in turn would make it harder to infer their individual financial conditions, mitigating the impact of the stigma effect. Finally, the corresponding allocation of funds is the only one that can be reached under a budgetbalanced program under the threat of side trading.

\section{Concluding Remarks}

We would like to conclude by mentioning two avenues for future research.

First, we have followed Rothschild and Stiglitz (1976) and many authors since in assuming that there are only two types of consumers. This, in particular, enabled us to directly compare our results to the characterization of the second-best efficiency frontier in Crocker and Snow (1985). Yet the question naturally arises to which extent our results are robust to this assumption. Attar, Mariotti, and Salanié (2019a) show that, in general, there exists a unique convex tariff for the planner that is entry-proof and implements a budget-feasible allocation. However, it is not straightforward to extend this uniqueness result to more than two types when the planner's tariff is nonconvex. ${ }^{3}$ Preliminary work suggests that imposing more structure on the consumers' preferences, as arises for instance in a Rothschild and Stiglitz (1976) economy, might be instrumental for such an extension.

Second, we have throughout the analysis postulated that, given the planner's tariff, an entrant can make a take-it-or-leave-it tariff offer to consumers. In that sense, bilateral trading is frictionless in our model. An alternative to this assumption, and to the standard Walrasian approach to side trading, would be to assume that bilateral trades are the outcome of a dynamic matching and bargaining game between firms and consumers searching for trade partners, in the spirit of Gale (2000). The planner may then be able to manipulate the outcome of this game by making search more costly, possibly enabling him to enlarge the set of implementable allocations and to achieve redistribution. More generally, the optimal manipulation of the market for side trades, which we have by assumption ruled out from our analysis, is an important topic for future investigations.

\footnotetext{
${ }^{3}$ Technically, this is because such a tariff may cause the consumers' indirect utility functions, as defined in the proof of Lemma 3, to fail to satisfy a single-crossing condition. Notice in any case that the existence of a budget-balanced allocation robust to side trading is always guaranteed.
} 


\section{Appendix}

Proof of Lemma 3. Each type $i$ evaluates any contract $\left(q^{E}, t^{E}\right)$ she can trade with the entrant through the indirect utility function

$$
z_{i}^{-P}\left(q^{E}, t^{E}\right) \equiv \max \left\{u_{i}\left(q^{P}+q^{E}, T^{P}\left(q^{P}\right)+t^{E}\right): q^{P} \geq 0\right\} .
$$

Because $u_{i}$ is strictly quasiconcave and $T^{P}$ is convex, the maximum in (A.1) is attained at a unique $\widehat{q}_{i}^{P}\left(q^{E}\right)$, and $\left(\widehat{q}_{i}^{P}\left(q^{E}\right), q_{i}^{E}\right)$ is a solution to (3) if and only if

$$
q_{i}^{E} \in \arg \max \left\{z_{i}^{-P}\left(q^{E}, T^{E}\left(q^{E}\right)\right): q^{E} \geq 0\right\} .
$$

According to Attar, Mariotti, and Salanié (2019b, Lemma 1), the convexity of the tariff $T^{P}$ and the strict single-crossing condition for the functions $u_{i}$ imply the following single-crossing condition for the functions $z_{i}^{-P}$ :

For all $\underline{q}^{E}<\bar{q}^{E}, \underline{t}^{E}$, and $\bar{t}^{E}, z_{1}^{-P}\left(\underline{q}^{E}, \underline{t}^{E}\right)<z_{1}^{-P}\left(\bar{q}^{E}, \bar{t}^{E}\right)$ implies $z_{2}^{-P}\left(\underline{q}^{E}, \underline{t}^{E}\right)<z_{2}^{-P}\left(\bar{q}^{E}, \bar{t}^{E}\right)$.

To conclude, suppose that $q_{2}^{E}<q_{1}^{E}$ at some solution $\left(\left(q_{i}^{P}, q_{i}^{E}\right)\right)_{i=1,2}$ to (3). By (A.2),

$$
z_{2}^{-P}\left(q_{2}^{E}, T^{E}\left(q_{2}^{E}\right)\right) \geq z_{2}^{-P}\left(q_{1}^{E}, T^{E}\left(q_{1}^{E}\right)\right) .
$$

Because $q_{2}^{E}<q_{1}^{E}$, the above single-crossing condition then implies

$$
z_{1}^{-P}\left(q_{2}^{E}, T^{E}\left(q_{2}^{E}\right)\right) \geq z_{1}^{-P}\left(q_{1}^{E}, T^{E}\left(q_{1}^{E}\right)\right)
$$

Thus $\left(\widehat{q}_{1}^{P}\left(q_{2}^{E}\right), q_{2}^{E}\right)$ is also a solution to (3) for type 1 . The result follows.

\section{References}

[1] Akerlof, G.A. (1970): "The Market for "Lemons": Quality Uncertainty and the Market Mechanism," Quarterly Journal of Economics, 84(3), 488-500.

[2] Allen, F. (1985): "Repeated Principal-Agent Relationships with Lending and Borrowing," Economics Letters, 17(1-2), 27-31.

[3] Attar, A., T. Mariotti, and F. Salanié (2011): "Nonexclusive Competition in the Market for Lemons," Econometrica, 79(6), 1869-1918.

[4] Attar, A., T. Mariotti, and F. Salanié (2014): "Nonexclusive Competition under Adverse Selection," Theoretical Economics, 9(1), 1-40.

[5] Attar, A., T. Mariotti, and F. Salanié (2019a): "Entry-Proofness and Market Breakdown under Adverse Selection," Toulouse School of Economics Working Paper No. 17-788. 
[6] Attar, A., T. Mariotti, and F. Salanié (2019b): "On Competitive Nonlinear Pricing," Theoretical Economics, 14(1), 297-343.

[7] Bierbrauer, F.J., and P.C. Boyer (2014): "The Pareto-Frontier in a Simple Mirrleesian Model of Income Taxation," Annals of Economics and Statistics, 113/114, 185-206.

[8] Bisin, A., and P. Gottardi (1999): "Competitive Equilibria with Asymmetric Information," Journal of Economic Theory, 87(1), 1-48.

[9] Bisin, A., and P. Gottardi (2006): "Efficient Competitive Equilibria with Adverse Selection," Journal of Political Economy, 114(3), 485-516.

[10] Bisin, A., and D. Guaitoli (2004): "Moral Hazard and Nonexclusive Contracts," RAND Journal of Economics, 35(2), 306-328.

[11] Caillaud, B., R. Guesnerie, P. Rey, and J. Tirole (1988): "Government Intervention in Production and Incentives Theory: A Review of Recent Contributions," RAND Journal of Economics, 19(1), 1-26

[12] Cole, H.L., and N.R. Kocherlakota (2001): "Efficient Allocations with Hidden Income and Hidden Storage," Review of Economic Studies, 68(3), 523-542.

[13] Crocker, K.J., and A. Snow (1985): "The Efficiency of Competitive Equilibria in Insurance Markets with Asymmetric Information," Journal of Public Economics, 26(2), $207-219$.

[14] Emanuel, E.J., and V.R. Fuchs (2005): "Health Care Vouchers-A Proposal for Universal Coverage," New England Journal of Medicine, 352(12), 1255-1260.

[15] Emanuel, E.J., and V.R. Fuchs (2007): "A Comprehensive Cure: Universal Health Care Vouchers," Discussion Paper No. 2007-11, Brookings Institution.

[16] Farhi, E., M. Golosov, and A. Tsyvinski (2009): "A Theory of Liquidity and Regulation of Financial Intermediation," Review of Economic Studies, 76(3), 973-992.

[17] Gale, D. (2000): Strategic Foundations of General Equilibrium: Dynamic Matching and Bargaining Games, Cambridge, UK: Cambridge University Press.

[18] Glosten, L.R. (1994): "Is the Electronic Open Limit Order Book Inevitable?" Journal of Finance, 49(4), 1127-1161.

[19] Golosov, M., and A. Tsyvinski (2007): "Optimal Taxation with Endogenous Insurance Markets," Quarterly Journal of Economics, 122(2), 487-534. 
[20] Gorton, G. (2015): "Stress for Success: A Review of Timothy Geithner's Financial Crisis Memoir," Journal of Economic Literature, 53(4) 975-995.

[21] Guesnerie, R. (1981): "On Taxation and Incentives: Further Reflections on the Limits to Redistribution," Discussion Paper, Institut für Gesellschafts- und Wirtschaftswissenschaften, Universität Bonn.

[22] Hammond, P.J. (1979): "Straightforward Individual Incentive Compatibility in Large Economies," Review of Economic Studies, 46(2), 263-282.

[23] Hammond, P.J. (1987): "Markets as Constraints: Multilateral Incentive Compatibility in Continuum Economies," Review of Economic Studies, 54(3), 399-412.

[24] Harris, M., and R.M. Townsend (1981): "Resource Allocation Under Asymmetric Information," Econometrica, 49(1), 33-64.

[25] Hellwig, M.F. (1988): "A Note on the Specification of Interfirm Communication in Insurance Markets with Adverse Selection," Journal of Economic Theory, 46(1), 154163.

[26] Hurwicz, L. (1973): "The Design of Mechanisms for Resource Allocation," American Economic Review, 63(2), 1-30.

[27] Jacklin, C.J. (1987): "Demand Deposits, Trading Restrictions, and Risk Sharing," in Contractual Arrangements for Intertemporal Trade, ed. by E.C. Prescott and N. Wallace. Minneapolis: University of Minnesota Press, 26-47.

[28] Jaynes, G.D. (1978): "Equilibria in Monopolistically Competitive Insurance Markets," Journal of Economic Theory, 19(2), 394-422.

[29] Kahn, C., and D. Mookherjee (1998): "Competition and Incentives with Nonexclusive Contracts," RAND Journal of Economics, 29(3), 443-465.

[30] Martimort, D. (2007): "Multi-Contracting Mechanism Design," in Advances in Economics and Econometrics: Theory and Applications, Ninth World Congress, Volume 1, ed. by R. Blundell, W.K. Newey, and T. Persson. Cambridge, UK: Cambridge University Press, 57-101.

[31] Mirrlees, J.A. (1971): "An Exploration in the Theory of Optimum Income Taxation," Review of Economic Studies, 38(2), 175-208. 
[32] Miyazaki, H. (1977): "The Rat Race and Internal Labor Markets," Bell Journal of Economics, 8(2), 394-418.

[33] Myerson, R.B. (1979): "Incentive Compatibility and the Bargaining Problem," Econometrica, 47(1), 61-73.

[34] Myerson, R.B. (1982): "Optimal Coordination Mechanisms in Generalized PrincipalAgent Problems," Journal of Mathematical Economics, 10(1), 67-81.

[35] Philippon T., and V. Skreta (2012): "Optimal Interventions in Markets with Adverse Selection," American Economic Review, 102(1), 1-28.

[36] Prescott, E.C., and R.M. Townsend (1984): "Pareto Optima and Competitive Equilibria with Adverse Selection and Moral Hazard," Econometrica, 52(1), 21-46.

[37] Rochet, J.-C. (1985): "The Taxation Principle and Multi-Time Hamilton-Jacobi Equations," Journal of Mathematical Economics, 14(2), 113-128.

[38] Rothschild, M., and J.E. Stiglitz (1976): "Equilibrium in Competitive Insurance Markets: An Essay on the Economics of Imperfect Information," Quarterly Journal of Economics, 90(4), 629-649.

[39] Rustichini, A., and P. Siconolfi (2008): "General Equilibrium in Economies with Adverse Selection," Economic Theory, 37(1), 1-29.

[40] Spence, M. (1978): "Product Differentiation and Performance in Insurance Markets," Journal of Public Economics, 10(3), 427-447.

[41] Stantcheva, S. (2014): "Optimal Income Taxation with Adverse Selection in the Labour Market," Review of Economic Studies, 81(3), 1296-1329.

[42] Stiglitz, J.E., J. Yun, and A. Kosenko (2018): "Characterization, Existence, and Pareto Optimality in Insurance Markets with Asymmetric Information with Endogenous and Asymmetric Disclosures: Revisiting Rothschild-Stiglitz," National Bureau of Economic Research Working Paper No. 24711.

[43] Thomson, S., and E. Mossialos (2009): "Private Health Insurance in the European Union," Studies and Reports on Health and Long-Term Care, European Commission, Brussels.

[44] Thomson, S., R. Osborne, D. Squires, and M. Jun (2013): "International Profiles of Health Care Systems, 2013," Commonwealth Fund Publication No. 1717, The Commonwealth Fund, New York. 
[45] Tirole, J. (2012): "Overcoming Adverse Selection: How Public Intervention Can Restore Market Functioning," American Economic Review, 102(1), 29-59.

[46] Wilson, C. (1977): "A Model of Insurance Markets with Incomplete Information," Journal of Economic Theory, 16(2), 167-207. 